\title{
O trabalho no fio da navalha: nova morfologia no Serviço Social em tempos de devastação e pandemia
}

\section{Work on the razor's edge: new morphology in Social Work in times of devastation and pandemic}

\author{
Raquel Raichelis ${ }^{a}$ \\ (D) https://orcid.org/0000-0003-3275-3755 \\ Carola C. Arregui \\ Dhttps://orcid.org/0000-0003-0533-554X
}

Resumo: $O$ artigo problematiza a confluência das crises desencadeadas pela epidemia do novo coronavírus e seus impactos no mundo do trabalho, no Serviço Social e no trabalho cotidiano de assistentes sociais, cujo desvendamento deve ser remetido à crise estrutural do capital das últimas décadas e às suas estratégias de enfrentamento.

Palavras-chave: Trabalho. Crise estrutural. Pandemia. Serviço Social. Teletrabalho.
Abstract: The article problematizes the confluence of crises triggered by the epidemic of the new coronavirus and its impacts on the world of work, social work and the everyday work of social workers, whose unveiling should be sent to the structural crisis of the capital of recent decades and their coping strategies.

Keywords: Work. Structural crisis. Pandemic. Social Work. Telework. 


\section{Introdução}

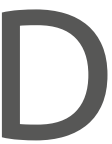

esde a primeira reportagem oficial do surto da covid-19, em Wuhan, na China, em dezembro de 2019, até finais de outubro de 2020, a pandemia atingiu 43 milhões de contágios e 1,1 milhão de vidas perdidas (Opas, 2020). O primeiro caso na América Latina foi reportado no Brasil, na cidade de São Paulo, em fevereiro de 2020, e em poucas semanas se alastrava para o conjunto dos países da região.

No mês de março, o mundo assistia atônito à rapidez com que o vírus se espalhava, o que originou o fechamento generalizado de fronteiras. Deflagravam-se os efeitos dos desmontes e da mercantilização dos sistemas de saúde mundiais, que, em pleno século XXI, evidenciaram carências rudimentares, como a falta de equipamentos de proteção individual e coletiva, insuficiência de instalações hospitalares e de recursos humanos e capacidade de cobertura insuficientes, requisitos absolutamente necessários aos cuidados sanitários da população. Tornou-se inevitável a implementação de diversas medidas de restrição de circulação, confinamento e quarentena, a fim de evitar o aumento da propagação do contágio. Nesse contexto, os grupos mais atingidos foram os segmentos mais vulnerabilizados e periféricos das classes trabalhadoras, em função das precárias condições de moradia, trabalho e vida que marcam seu cotidiano. As referências à crise sanitária, à estagnação e crise econômica, ao aumento do desemprego e à crise social tornaram-se o centro das manchetes, e preocupações e angústias de grande parte da população ao redor do planeta. Situações inusitadas para as quais o mundo não estava preparado e, portanto, não tinha respostas.

Entretanto, a origem da crise em curso não está na covid-19, mas nas lógicas e configurações do sistema de metabolismo antissocial do capital, nos termos de Antunes (2020a e 2000b), que já estavam em desenvolvimento desde a década de 1970 e que se aprofundaram com as crises de 2007 e 2008.

É com esse quadro de referências que pretendemos problematizar a confluência das crises desencadeadas pela epidemia do novo coronavírus e seus impactos no mundo do trabalho, no Serviço Social e no trabalho 
cotidiano de assistentes sociais, cujo desvendamento deve ser remetido à crise estrutural do capital das últimas décadas e às suas estratégias de enfrentamento.

\section{A crise deflagrada pela covid-19 e o contexto latino-americano pré-pandemia}

Rob Wallace (2020) argumenta que as origens da atual pandemia de covid-19, assim como das diversas outras epidemias dos últimos anos, residem na globalização das práticas predatórias do agronegócio, mais especificamente na pecuária intensiva, cujos efeitos colaterais abrangem a produção de catástrofes ecológicas, epidemias e pandemias cada vez mais comuns e destrutivas. $\mathrm{O}$ aumento da ocorrência dos vírus estaria, para Wallace (2020), intimamente ligado à produção alimentar e à rentabilidade das empresas transnacionais, numa lógica de desenvolvimento de commodities e de usurpação de terras e recursos naturais, que buscam a maximização de lucros, independentemente dos riscos sanitários e humanos decorrentes desse modo de acumulação de capital. O domínio do capital financeiro e o impacto das biotecnologias sob a racionalidade da maximização do lucro resultaram, desde o final da década de 1970, num processo crescente de aquisições e fusões em larga escala, transformando a geografia histórica do capitalismo, que se aprofunda com a crise econômica mundial de 2008 (Harvey, 2011). Verdadeiros oligopólios transnacionais controlam a produção de alimentos, sementes, fertilizantes, agrotóxicos, mas também de produtos farmacêuticos, dos derivados do petróleo e da produção vinculada ao desenvolvimento de biotecnologias e sistemas informacionais.

Segundo o Atlas do agronegócio (Santos e Glass, 2018), o Brasil é um dos países do mundo onde mais se evidencia a concentração na produção de alimentos: entre $60 \%$ e $70 \%$ das compras de uma família brasileira derivam do processo de produção, distribuição e circulação entre apenas dez empresas de capital transnacional. A incorporação da tecnologia 
com vistas à maximização do lucro sem limites, por meio da mecanização e digitalização da produção agrícola e pecuária, deriva na dispensa cada vez maior de trabalhadores(as), no aumento da precarização das condições de trabalho na cadeia produtiva (que envolve desde o setor agrícola, passando pela indústria e chegando aos serviços), e na reedição das formas de trabalho análogas à escravidão. $O$ estudo evidencia que 0 agronegócio, como um dos pilares da economia de muitos países do Sul global, e em especial da brasileira, vem crescendo na base da espoliação da força de trabalho, da concentração e expropriação violenta de terras e da destruição da natureza.

A crise sanitária, econômica e social que assola o mundo no início do século XXI está imbrincada com as profundas modificações do capitalismo na sua forma de organização e de atuação econômica, social e política, tendo como base o capital imperalismo (Fontes, 2010), cujos traços fundamentais são: predomínio do capital monetário e seu impulso avassaladoramente expropriador; aumento da concentração e centralização do capital; presença de propriedade capitalista altamente transnacionalizada e difusa; captura de todos os recursos disponíveis e todas as atividades humanas para a sua transformação em forma de produção e extração de valor.

É nesse contexto que na divisão internacional do trabalho a América Latina retorna à sua condição de exportadora de matérias-primas e alimentos, sob o novo padrão exportador de especialização produtiva (Osório, 2012) na base do extrativismo e, portanto, da expropriação dos seus recursos naturais. $O$ modo de acumulação do capital na região agrava e apresenta novos contornos no conjunto de expropriações (Harvey, 2005), expressos na destruição da força de trabalho; na usurpação da terra e da biodiversidade das suas selvas e florestas; no saqueio dos seus bens, recursos e serviços públicos (com especial foco, em função da crise de 2008-9, para uma nova leva de privatizações e mercantilização, por parte do capital transnacional, dos fundos de pensão, da previdência e da educação), além do ataque e avanço de políticas agressivas de eliminação de direitos sociais e trabalhistas. 
-Segundo o IBGE (2019), o percentual de trabalhadores informais chegou, em 2019, a 41,3\% do total da população ocupada, e a incidência de trabalhadores e trabalhadoras que prestavam serviços, ocultos na categoria de trabalhadores por conta própria, mas vinculados a empresas de aplicativos e plataformas digitais, tinha crescido 29,2\% de 2017 para 2018, evidenciando a progressiva expansão da uberização do trabalho. ${ }^{1}$

O relatório da Oxfam Brasil (2017), intitulado A distância que nos une: um retrato das desigualdades brasileiras, escancarou a distância que, de fato, aparta a sociedade brasileira, quando apenas seis pessoas possuem riqueza equivalente ao patrimônio de 100 milhões de brasileiros e quando os $5 \%$ mais ricos detêm a mesma fatia de renda que os demais 95\% da população (Oxfam, 2017, p. 6). ${ }^{2}$

Desigualdade estrutural que se produz e reproduz num contexto cada vez mais antagônico à concepção de direitos humanos e se materializa nos mais diversos tipos de violências e violações contra a população negra, contra a população indígena, contra jovens negros(as), pobres e periféricos(as), contra a população LGTBI+, contra a mulher, contra os imigrantes, contra a classe trabalhadora; em suma, contra a maioria da população brasileira. A expressão máxima fica evidente no país quando o presidente trata um problema sanitário mundial de proporções inusitadas como uma "gripezinha", enquanto o número de mortes pela covid-19 alcançou, até meados de outubro de 2020, 160 mil pessoas.

A eclosão do novo coronavírus, em meio à profunda crise estrutural do capital, acentuará exponencialmente seus traços sistêmicos em curso, articulando em uma totalidade contraditória suas dimensões econômica, política, social e sanitária.

\footnotetext{
Segundo Abílio (2020, p. 111), o termo uberização, embora inspirado pela empresa de aplicativo global, "não se inicia com a Uber nem se restringe a ela", expressando "uma nova forma de controle, gerenciamento e organização do trabalho e uma tendência global que também poderia ser denominada informalização do trabalho ou, mais precisamente, consolidação dos trabalhadores just-in-time.

2 Distâncias que se alimentam da desigualdade estrutural de gênero e raça/etnia, considerando que a renda média da mulher representava $40 \%$ a menos que a auferida pelo homem e que a renda média da população preta ou parda era $50 \%$ a menos que a da população branca.
} 


\section{A (nova) morfologia do trabalho no contexto da pandemia: o admirável velho mundo novo ${ }^{3}$}

Como já anunciado, a pandemia do novo coronavírus não é responsável pela emergência da crise contemporânea, mas certamente exacerbou os traços mais perversos de uma crise social de grandes proporções, tornando mais tangíveis e mais visíveis processos que já estavam em desenvolvimento. A ideia central de nosso argumento é que a crise sanitária desnudou a forma pela qual o capitalismo vinha respondendo às suas crises há cerca de quatro décadas, desde os anos 1970, como estratégia do capital para reverter a queda tendencial das taxas de lucro, em um movimento estrutural de superprodução e subconsumo.

Sabemos que as crises no capitalismo não são fenômenos eventuais, mas constitutivos do movimento sociometabólico do capital. Nesse processo, o capital incorpora as inovações e os avanços tecnológicos e científicos, especialmente as tecnologias de base digital, que aceleram a produtividade do trabalho, provocam a economia de trabalho vivo e ampliam a população sobrante para as necessidades médias de valorização do capital, ampliando e diversificando a superpopulação relativa (Marx, 1968 e 1975). Dinâmica que aprofunda as taxas de desemprego e de precarização do trabalho em escala mundial.

Nesses termos, a precarização do trabalho não é uma fatalidade, como muitos(as) querem fazer crer, mas uma estratégia do padrão de acumulação capitalista em tempos de mundialização neoliberal, tanto no centro quanto na periferia dependente. Trata-se de um poderoso mecanismo de reorganização do trabalho no contexto do capitalismo hegemonizado pelas finanças, que combina flexibilização, terceirização e informalidade do trabalho "como partes inseparáveis do léxico e da pragmática da empresa corporativa global” (Antunes, 2020b, p. 11).

Mesmo que a precariedade do trabalho seja um requisito inerente ao capitalismo, sua processualidade foi se transformando historicamente,

3 Expressão utilizada por Ludmila C. Abílio no texto “Uberização: gerenciamento e controle do trabalhador just in time, 2020, p. 115. 
assumindo na contemporaneidade capitalista traços de um movimento permanente de perdas, regressão social, ofensiva contra os trabalhadores, superexploração da força de trabalho em âmbito mundial, com expressões nefastas na periferia dependente. Portanto, "a precarização social do trabalho é um novo e um velho fenômeno, porque é diferente e igual, porque é passado e presente e porque é um fenômeno de caráter macro e microssocial" (Druck, 2011, p. 35).

No caso da América Latina, essa dinâmica ganha configurações mais profundas e estruturantes. Tomando como referência o Brasil, ao contrário do que aconteceu historicamente com o capitalismo nos países centrais, o Estado brasileiro não criou condições para a reprodução social da totalidade da força de trabalho, nem estendeu direitos de cidadania ao conjunto da classe trabalhadora, excluindo imensas parcelas de trabalhadores e trabalhadoras do acesso ao trabalho protegido e às condições de reprodução social da força de trabalho.

A precarização do trabalho assume novas dimensões e manifestações na atualidade, atingindo o conjunto da classe trabalhadora, ainda que com diferentes intensidades, considerando-se a divisão sociotécnica, sexual e étnico-racial do trabalho. No âmbito das relações trabalhistas, desde os anos 1990 experimenta-se um processo permanente de erosão do trabalho contratado, regulado e protegido dominante no século $\mathrm{XX}$, mesmo que no Brasil tenha se instalado um Estado de mal-estar social, nos termos do saudoso professor Francisco de Oliveira, que jamais universalizou o trabalho assalariado e os direitos daí decorrentes, desnudando a matriz do nosso capitalismo escravocrata, patrimonialista, patriarcal e genocida.

Ao mesmo tempo, constata-se nessa quadra histórica a disseminação do neoliberalismo hiperautoritário como "a nova razão do mundo" (Dardot e Laval, 2016), agravado no Brasil recente por uma versão fundamentalista do neoliberalismo com traços neofascistas (Löwy, 2020).

A pandemia ocorre em uma conjuntura em que já tínhamos um quadro cumulativo e alarmante de informalidade, desemprego e desproteção laboral no mercado de trabalho brasileiro, agravado no contexto do "capitalismo pandêmico" ou "capitalismo tóxico e virótico" (Antunes, 
2020a), uma vez que combina crescentes níveis de exploração e degradação humanas à destruição sistemática do meio ambiente.

Em julho de 2020, os dados do IBGE (2020) revelavam o aumento para mais de $50 \%$ da força de trabalho (52 milhões de pessoas) entre desocupados, desalentados e subutilizados no mercado de trabalho brasileiro. ${ }^{4}$ Situação que se agrava ainda mais se considerarmos dimensões de gênero, raça e etnia, pois sabemos que os salários das mulheres são menores do que o dos homens que exercem a mesma atividade; e se forem pretas e pardas, serão submetidas a trabalhos mais precários e a salários ainda mais baixos.

Trata-se, porém, de um quadro que tende a piorar nos próximos meses. De um lado, porque apenas começam a ser sentidos os impactos da redução do auxílio emergencial (de $R \$$ 600,00 para $R \$ 300,00$ ) e sua extinção no final do ano de 2020. E, de outro, porque com a flexibilização das medidas de isolamento social, as pessoas que perderam o emprego e não estavam saindo para procurar em função da pandemia começarão a fazê-lo daqui para a frente, passando a figurar nas estatísticas, pois o IBGE só considera desempregado quem está em busca de emprego. ${ }^{5}$ Ao mesmo tempo, essa dinâmica societária transformou a composição e o perfil da classe trabalhadora, tornando-a mais heterogênea, compósita e complexa (Antunes, 1999, 2020a e 2020b), o que cria enormes desafios políticos para os sindicatos e entidades representativas da classe trabalhadora construírem pautas coletivas que representem os interesses e as necessidades desse conjunto diversificado de trabalhadores e trabalhadoras.

Por outro lado, agregou-se à crise econômica e sanitária a prolongada crise política brasileira, tendo como marco o golpe jurídico-parlamentar-midiático de 2016, que destituiu a presidente Dilma Rousseff, eleita democraticamente com mais de 50 milhões de votos. Com o governo ilegítimo de Temer, foi implementado um amplo programa de

\footnotetext{
4 A taxa de desemprego atingiu 13,8\% (13,1 milhões de pessoas), o maior índice dos últimos trinta anos; 5,8 milhões de desalentados e 32,9 milhões de subutilizados.

5 A PNAD de setembro (IBGE, 2020) revela que a taxa de desemprego alcançou o patamar recorde de $14,4 \%$ no geral e de $16,4 \%$ entre os jovens de 18 a 24 anos.
} 
contrarreformas que materializou uma dura ofensiva contra os direitos da classe trabalhadora a serviço dos interesses do grande capital transnacional e das burguesias nacionais associadas.

Entre as contrarreformas, destaca-se a EC no 95/2016, conhecida como a "PEC do fim do mundo", que estabeleceu o novo regime fiscal com o congelamento dos gastos públicos por vinte anos, medida inédita em termos mundiais, que impacta drasticamente nas políticas e nos programas sociais em todas as áreas. Acrescente-se a esse quadro a flexibilização da legislação protetora do trabalho, que fragiliza a organização coletiva dos(as) trabalhadores(as) e suas resistências, a desconstrução da CLT e a terceirização irrestrita; a contrarreforma da Previdência Social; e, nesse momento, encontra-se na pauta da Câmara Federal o projeto de contrarreforma administrativa (PEC no 32/2020), cuja finalidade é desconstruir o regime jurídico único, as carreiras públicas do Estado e a estabilidade do servidor público, com impactos na qualidade dos serviços públicos.

Esse conjunto de medidas articula-se a uma profunda e persistente desigualdade na distribuição das rendas e das riquezas provenientes do trabalho e a quase inexistente tributação das altas rendas, dos lucros e dividendos, somado à política tributária altamente regressiva, que faz com que a carga de impostos recaia sobre a maioria dos(as) trabalhadores(as).

E, completando esse quadro nefasto, desde janeiro de 2019 convivemos com o (des)governo Bolsonaro, que reafirma o compromisso com as oligarquias financeiras e o grande capital internacional, aprofundando a inserção subordinada do Brasil ao governo de direita ultraneoliberal dos EUA.

Trata-se de um (des)governo de traços neofascistas, que reforça o braço repressivo do Estado e ameaça reiteradamente o rompimento da ordem constitucional. A isso somam-se o fundamentalismo religioso e obscurantista, o negacionismo da ciência, os irracionalismos, as práticas neofascistas que impõem o social-darwinismo e a necropolítica como modus operandi.

Portanto, nesse contexto de tríplice crise - econômica, política e sanitária -, explicita-se a ruptura do pacto social construído em torno 
da Constituição Federal de 1988 (especialmente na Seguridade Social), com base na ideia de que ela não cabe no orçamento, que os direitos sociais oneram demais o fundo público e que o enfrentamento da crise é de responsabilidade de toda a sociedade. Decorrem daí os apelos ao empreendedorismo, ao solidarismo social, à solidariedade do capital.

A situação de pandemia expõe com muita crueza as dimensões contraditórias desse processo: de um lado, a falência das medidas ultraneoliberais que desfinanciaram as políticas sociais, especialmente o SUS e o Suas, os sistemas de proteção social mais requisitados no contexto da pandemia. E, ao mesmo tempo, a necessidade de mais Estado e do fortalecimento das políticas públicas para enfrentamento dessa grave crise.

\section{A (nova) morfologia do trabalho no Serviço Social: TIC no trabalho e na formação profissional}

As metamorfoses no "mundo" do trabalho, como vimos analisando, incidem no mercado de trabalho do Serviço Social e no exercício profissional de assistentes sociais e demais profissionais, em uma contextualização de degradação do trabalho e precarização das condições em que ele é exercido, impactando não apenas as condições materiais dos sujeitos que vivem do trabalho, mas também suas sociabilidades individual e coletiva, considerando ainda a erosão dos sistemas públicos de proteção social, lugar institucional privilegiado onde operam os(as) trabalhadores(as) sociais.

O ponto a ser destacado é que essa a nova-velha morfologia do trabalho repercute e reconfigura o trabalho social de diferentes categorias profissionais, entre elas assistentes sociais, que têm nas políticas públicas sua mais ampla inserção. O quadro de pandemia traz novos elementos àqueles que vínhamos discutindo (Raichelis, 2018 e 2019), atingindo o núcleo das atribuições e competências profissionais e desencadeando inúmeras pressões e tensões aos(às) assistentes sociais nos diferentes espaços de trabalho. 
Os variados estudos, levantamentos, depoimentos, bem como o acompanhamento atento do debate profissional em diversos espaços ocupacionais, públicos e privados, evidenciam, de um lado, o medo, as pressões, as angústias reais de assistentes sociais, especial, mas não exclusivamente, daqueles(as) que estão na linha de frente do trabalho presencial; e de outro, os sofrimentos e adoecimentos desencadeados em todos(as), tanto no trabalho presencial quanto no remoto, em meio à impotência para fazer frente às expressões mais dramáticas da questão social e às necessidades urgentes dos indivíduos e famílias que demandam atenção pública.

No que se refere às condições e relações de trabalho, assistentes sociais, na condição de trabalhadores(as) assalariados(as), são submetidos(as) aos mesmos processos de degradação e violação de direitos que sofre o conjunto da classe trabalhadora, no interior da heterogeneidade que a caracteriza. Dentre esses processos, ao lado do(a) servidor(a) público, estatutário com contrato regido por regime jurídico próprio (profundamente atacado nesse momento), encontramos os mais variados vínculos contratuais, entre os quais: os chamados PJs ou "pejotização" no jargão da área; a terceirização; o trabalho temporário; o trabalho em tempo parcial, por tarefa, por projeto; o trabalho intermitente, entre outros.

Essa heterogeneidade - que tipifica o processo continuado de reestruturação produtiva do trabalho e do capital, caracterizado pelas diversas formas de contratação, de organização e de processamento do trabalho - expressa a nova morfologia ou a "uberização" do trabalho, como vem sendo denominado esse amplo movimento de mudanças que atinge o trabalho no capitalismo contemporâneo. E é preciso considerar que não se trata apenas da empresa Uber, mas, como observado anteriormente, da forma contemporânea do trabalho degradado e superexplorado que se dissemina amplamente para todos os setores e nichos do mercado de trabalho, com intensa incorporação das tecnologias de informação e comunicação (TIC).

São processos que promovem a mais profunda metamorfose no mercado de trabalho profissional, mesmo no espaço estatal das políticas 
públicas, estimulando a individualização do trabalho, as formas de avaliação de desempenho baseado em metas de produtividade e remuneração diferenciada, promovendo competição entre trabalhadores e desmobilização coletiva.

No quadro pandêmico atual, o que era residual e embrionário, como o trabalho remoto ou o teletrabalho, generalizou-se como o "novo normal" - que não deve ser naturalizado - , exigindo acompanhamento crítico, pois certamente muitas dessas modalidades de trabalho, adotadas na situação de excepcionalidade, tendem a permanecer mesmo após a pandemia, inclusive no trabalho docente. Trata-se de um conjunto de novas situações de trabalho impostas de cima para baixo na maioria das instituições, mesmo nas universidades.

Nessa ambiência institucional ganham maior abrangência e centralidade as TIC, que promovem novas formas de subsunção do trabalho aos interesses do capital (Marx, 1968 e 1975) e de seus representantes no aparelho de Estado. 0 trabalho remoto, o home office ou o teletrabalho, que produzem o trabalhador just in time (Abílio, 2020), e já vinham sendo adotados de forma residual, embora crescente, nos diferentes espaços sócio-ocupacionais, se generalizaram com as medidas de isolamento social. Em algumas instituições, como no INSS e no Tribunal de Justiça, o teletrabalho já estava em experimentação na modalidade de trabalho no domicílio, cercado de polêmicas e de certa naturalização por parte de alguns profissionais, com o objetivo declarado de aumentar a eficiência e a produtividade.

Em relação ao teletrabalho, cabe esclarecer que no contexto da "reforma trabalhista" de 2017 instituiu-se na CLT um capítulo específico sobre essa modalidade de trabalho remoto, podendo ser realizado por meio de contrato por tempo determinado ou indeterminado. ${ }^{6}$ Como observam Praun

6 O artigo no 75-B da CLT passa a considerar como teletrabalho "a prestação de serviços preponderantemente fora das dependências do empregador, com a utilização de tecnologias de informação e de comunicação que, por sua natureza, não se constituam como trabalho externo". 
e Antunes (2020, p. 183 ss), há no texto algumas especificações sobre o teletrabalho, mas não há nenhum detalhamento a respeito da duração da jornada de trabalho dos(as) "teletrabalhadores"(as), nem quanto à responsabilidade pelos equipamentos tecnológicos e infraestrutura necessária para o exercício das atividades remotas, relegando-se ao(à) trabalhador(a) o cuidado de prevenir-se contra doenças e acidentes de trabalho.

Portanto, o trabalho remoto, apoiado nas TIC, além de se realizar em espaços inadequados (afinal, a casa não foi criada para o trabalho), transfere os custos aos(às) próprios(as) trabalhadores(as) (internet, pacote de dados, manutenção do computador, energia elétrica etc.) e traz maior impacto sobre as mulheres, pois, na tradicional divisão sexual do trabalho, são elas que assumem a responsabilidade pelas atividades domésticas, cuidados com crianças, idosos e doentes, sofrendo maior invasão do tempo de trabalho na vida privada.

O teletrabalho, mediado por plataformas digitais, não apenas favorece novas formas de controle e vigilância dos processos e resultados do trabalho pelo empregador, como transfere o gerenciamento do trabalho para o próprio trabalhador para o alcance de metas de produtividade nem sempre alcançáveis. Nesse tipo de gestão por pressão ocorre a intensificação do trabalho, com impactos na materialidade e na subjetividade dos(as) trabalhadores(as): ampliação da jornada de trabalho para dez, doze horas, fadiga pelo tempo excessivo de permanência em frente à tela do computador, multiplicação do número de reuniões até a exaustão, simbiose entre tempo de trabalho e de não trabalho. Contexto favorável ao crescimento do assédio moral, desgaste mental, adoecimentos provocados pelas novas formas de gerenciamento e controle dos processos de trabalho (Raichelis e Vicente, 2019).

O trabalho profissional e seus sujeitos encontram-se tensionados pelas novas situações decorrentes do isolamento social, vivenciadas por indivíduos e famílias que transitam pela condição de trabalhadores(as) informais, precarizados(as), intermitentes, com predomínio de pretos(as) e pardos(as), acompanhando as estatísticas gerais que tipificam a população brasileira para os grupos mais pobres, com destaque para as mulheres. 
Seu traço definidor é a desigualdade e uma emblemática condição de subalternidade, que repercute, em muitos casos, na aceitação das regras institucionais como se fossem naturais. Ao mesmo tempo, é preciso considerar as condições sociais e materiais da população atendida pelas políticas públicas, bem como as implicações quando não dispõem de celular e/ou computador com acesso à internet e recursos para acesso on-line.

Assim, estão em jogo questões éticas relevantes, que colocam em confronto direitos dos(as) profissionais de realizar seu trabalho com segurança e proteção à vida e os direitos dos(as) usuários(as) de terem atendidas suas necessidades no momento em que mais necessitam de apoio, em que estão submetidos(as) à violação de direitos, violência doméstica contra a mulher, abusos sexuais contra crianças e adolescentes, violência contra idosos e pessoas com deficiência.

Em meio a esse quadro agravado pela pandemia, considerando a sua dimensão contraditória, o uso das TIC também tem sido potente para promover atividades essenciais, como: contatos e informações a familiares de pacientes internados; conversas de pessoas presas com seus familiares por meio de tablets doados; articulação com serviços e rede socioassistencial nos territórios de moradia; circulação de informações; novas interações intersetoriais; maior interlocução entre profissionais, equipes e setores, antes distanciados.

Ao mesmo tempo, há um impacto profundo na forma de ser do trabalho profissional, que se materializa por meio da relação presencial, dialógica e político-pedagógica com os sujeitos com os quais assistentes sociais trabalham e para os quais prestam serviços profissionais.

Portanto, embora o capital se aproprie hegemonicamente das tecnologias digitais para ampliar os níveis de produtividade e de superexploração do trabalho, é preciso adotar estratégias para tensionar e utilizar essas tecnologias na perspectiva contra-hegemônica de fortalecimento dos valores ético-políticos que orientam o projeto profissional.

Nesse contexto, é fundamental que os(as) profissionais definam técnica e eticamente o que não é possível realizar na modalidade de 
teletrabalho, o que é possível realizar e em que condições, para que sejam garantidos segurança no trabalho, qualidade no atendimento, sigilo profissional, respeito aos direitos de usuários(as) e trabalhadores(as). Se assim não for, certamente essas decisões serão impostas pelo poder institucional durante e após a pandemia.

É importante ter presente que a generalização do teletrabalho na pandemia está funcionando para as empresas e instituições públicas e privadas, entre elas as universidades, como um grande laboratório. E sua continuidade pós-pandemia, defendida abertamente pelos(as) dirigentes institucionais para economizar custos e aumentar a produtividade do trabalho, poderá contar, como várias pesquisas vêm apontando, com a aprovação dos(as) próprios(as) trabalhadores(as).

No caso do trabalho docente no contexto da pandemia, aprofunda-se o ensino via plataformas digitais, com significativas mudanças em virtude da imbricação entre trabalho vivo e trabalho morto e a subsunção real do trabalho ao capital (Marx, 1968 e 1975), principalmente no ensino privado, hegemonizado pelo grande capital transnacional e pelos conglomerados econômicos, para os quais a educação é um grande negócio, com capital na bolsa e rentabilidade controlada pelos acionistas. ${ }^{7}$

O impacto das TIC e das novas formas de gestão empresarial e gerencialista das políticas educacionais e do trabalho docente é imenso e diversificado: no tipo de contrato uberizado (temporário, intermitente, terceirizado); na expansão ilimitada do número de alunos por turma; na expropriação do saber docente; na perda de autonomia acadêmica para tomada de decisões sobre procedimentos pedagógicos, definição de conteúdo, material didático, metodologias de avaliação etc.

Diante do quadro de crise sanitária e econômica, é necessário resistir à naturalização da racionalidade tecnológica associada aos interesses de

Caso emblemático é o do Grupo Laureate, conglomerado de universidades que opera as Faculdades Unidas Metropolitanas (FMU) e Anhembi Morumbi, que acaba de anunciar a venda de suas operações no Brasil para a Anima Holding, em uma negociação estimada em R $\$$ 4,6 bilhões. 
mercantilização da educação e da pesquisa. Contudo, o ensino remoto, para além da situação emergencial desencadeada pela pandemia, está em processo de incorporação maciça na educação superior, contexto que exige posicionamento crítico frente às alternativas apresentadas, como o denominado "ensino híbrido", que pode constituir-se em porta de entrada/ expansão da EAD, tanto nas universidades privadas como nas públicas. Também é imprescindível o reconhecimento das condições de vida e de trabalho dos(as) estudantes e de suas famílias, no sentido do suporte e provimento àqueles(as) com dificuldades de acesso ao computador, smartphone, pacote de dados, rede de internet com banda larga, bem como o acolhimento aos(às) estudantes que já estão apresentando sinais de desgaste psicológico e adoecimento. ${ }^{8}$

\section{Uma nota final}

A despeito dos ataques que o trabalho vêm sofrendo, estamos acompanhando inúmeras situações de alianças entre pares, solidariedade de classe nas favelas, nas periferias, nos movimentos populares que sinalizam diferentes iniciativas de organização coletiva que a pandemia tem desencadeado e que é preciso conhecer, socializar e potencializar.

A proximidade do Serviço Social e seus(as) trabalhadores(as) com diferentes segmentos das classes trabalhadoras e populares cria condições para o conhecimento das suas reais necessidades, seus modos de vida, de trabalho e de luta pela sobrevivência, suas fragilidades e fortalezas lapidadas pelo duro cotidiano. A socialização de informações, assim como a denúncia sobre violação de direitos, são instrumentos potentes a ser mobilizados.

\footnotetext{
8 Pesquisas conduzidas pela representação de pós-graduandos(as) na Abepss, que precisam ser debatidas e socializadas, têm evidenciado situações de profundo desgaste mental e emocional, bem como de adoecimento entre estudantes, potencializadas pelos cortes de bolsas e do fomento à pesquisa e à pós-graduação no país, agravadas no contexto da pandemia.
} 
O cotidiano profissional é marcado por tensões e desafios, mas é nesse mesmo cotidiano que se apresentam as possibilidades de superação e enfrentamento das requisições impostas, às quais os(as) assistentes sociais não estão obrigados(as) a se submeter, dispondo de autonomia relativa para propor e negociar suas propostas profissionais.

Para fazer frente a essa conjuntura desafiadora que interpela trabalhadores(as) e entidades de representação profissional e acadêmica, é fundamental ampliar e multiplicar os fóruns e debates coletivos, mesmo que virtuais, internos e externos ao Serviço Social. E resgatar o sentido de pertencimento de classe e alianças com forças coletivas de resistência.

\section{Referências}

ABÍLIO, Ludmila C. Uberização: gerenciamento e controle do trabalhador just in time. In: ANTUNES, R. (org.). Uberização, trabalho digital e indústria 4.O. São Paulo: Boitempo, 2020. ANTUNES, Ricardo. Os sentidos do trabalho: ensaios sobre a afirmação e a negação do trabalho. São Paulo: Boitempo, 1999.

ANTUNES, Ricardo. O privilégio da servidão: o novo proletariado de serviços na era digital. São Paulo: Boitempo, 2018.

ANTUNES, Ricardo. Coronavírus: o trabalho sob fogo cruzado. São Paulo: Boitempo: 2020a.

ANTUNES, Ricardo. Trabalho intermitente e uberização do trabalho no limiar da Industria 4.0. In: ANTUNES, R. (org.) Uberização, trabalho digital e indústria 4.0. São Paulo: Boitempo, 2020b.

BRAZ, Marcelo. 0 golpe nas ilusões democráticas e a ascensão do conservadorismo reacionário. Serviço Social @ Sociedade, São Paulo, n. 128, p. 85-103, abr. 2017. Disponível em: https://www.scielo.br/pdf/sssoc/n128/0101-6628-sssoc-128-0085.pdf. Acesso em: 21 set. 2020.

DARDOT, Pierre; LAVAL, Christian. A nova razão do mundo: ensaio sobre a sociedade neoliberal. São Paulo: Boitempo, 2016.

DRUCK, Graça. Trabalho, precarização e resistências: novos e velhos desafios? Caderno CRH, Salvador, v. 24, n. spe1, p. 35-55, 2011. Disponível em: https://www.scielo.br/scielo. php?script=sci_arttext\&pid=S0103-49792011000400004\&lng=pt\&nrm=iso\&tlng=pt. Acesso em: 15 mar. 2017. 
FONTES, Virgínia. O Brasil e o capital imperialismo: teoria e história. Rio de Janeiro: EPSJV/Editora UFRJ, 2010.

HARVEY, David. El "nuevo" imperialismo: acumulación por desposesión. Buenos Aires: Clacso, 2005.

HARVEY, David. O enigma do capital e as crises do capitalismo. São Paulo: Boitempo, 2011.

IBGE. Pesquisa Nacional por Amostra de Domicílios Contínua. Rio de Janeiro: IBGE, 2019. Disponível em: https:/www.ibge.gov.br/estatisticas/sociais/trabalho/9171-pesquisanacional-por-amostra-de-domicilios-continua-mensal.html?edicao=26737\&t=destaques. Acesso em: 30 jul. 2020.

IBGE. Pesquisa Nacional por Amostra de Domicílios Contínua. Rio de Janeiro: IBGE, 2020. Disponível em: https:/www.ibge.gov.br/estatisticas/sociais/trabalho/9171-pesquisanacional-por-amostra-de-domicilios-continua-mensal.html?=\&t=o-que-e. Acesso em: 30out. 2020.

MARX, Karl. O capital (Crítica da economia política). São Paulo: Civilização Brasileira, 1968. Livro 1, v. 1 e 2.

MARX, Karl. Capítulo inédito de O capital: resultados do processo de produção imediato. Porto (Portugal): Publicações Escorpião, 1975.

OXFAM. Terra, poder e desigualdade na América Latina. 2016. Disponível em: https:// www.oxfam.org.br/sites/default/files/arquivos/terra_desigualdade-resumo_executivo-pt. pdf. Acesso em: 29 set. 2020.

OXFAM. A distância que nos une. Um retrato das desigualdades brasileiras. 2017. Disponível em: https://www.oxfam.org.br/um-retrato-das-desigualdades-brasileiras/adistancia-que-nos-une/?gclid=CjOKCQiAwf39BRCCARIsALXWETww20E58ygVmAtt7YFv 5CFJO2UgPpPoC1tmCXOxHRXqqxP-YuWYbREaArvBEALw_wcB. Acesso em: 20 set. 2020.

LÖWY, Michael. Isto se chama genocídio. Disponível em: https://leonardoboff. org/2020/04/30/michael-lowyisto-se-chama-genocidioneofascista-bolsonaro-diante-dovirus/. Acesso em: 30 abr. 2020.

OPAS. Folha informativa Covid-19. Escritório Regional no Brasil, Organização PanAmericana da Saúde, Organização Mundial da Saúde, 2020. Disponível em: https://www. paho.org/pt/covid19. Acesso em: 12 out. 2020.

OSÓRIO, Jaime. América Latina: o novo padrão exportador de especialização produtiva. In: FERREIRA, Carla; OSÓRIO, Jaime, LUCE, Mathias (orgs.). Padrão de reprodução do capital: contribuições da teoria marxista da dependência. São Paulo: Boitempo, 2012.

PRAUN, Luci. A demolição dos direitos do trabalho na era do capitalismo informacionaldigital. In: ANTUNES, R. (org.). Uberização, trabalho digital e indústria 4.0, op. cit. 
RAICHELIS, Raquel. Serviço Social: trabalho e profissão na trama do capitalismo contemporâneo. In: RAICHELIS R. et al. (orgs.). A nova morfologia do trabalho no Serviço Social. São Paulo: Cortez, 2018.

RAICHELIS, Raquel. Atribuições e competências profissionais revisitadas - A nova morfologia do trabalho no Serviço Social. In: COMISSÃO DE ORIENTAÇÃO E FISCALIZAÇÃO PROFISSIONAL (COFI/CFESS). Atribuições privativas do/a assistente social em questão. Brasília: CFESS, 2019.

RAICHELIS, Raquel; VICENTE, Damares. Contrarreforma trabalhista no Brasil: desproteção da classe trabalhadora e desmanche de direitos. In: SILVA, Ademir Alves; PAZ, Rosângela D. Oliveira (orgs.). Políticas públicas e direitos sociais no contexto da crise capitalista contemporânea. São Paulo: Paulinas, 2019.

SANTOS, Maureen; GLASS, Verena (orgs.). Atlas do agronegócio: fatos e números sobre as corporações que controlam o que comemos. Rio de Janeiro: Fundação Heinrich Böll; São Paulo: Fundação Rosa Luxemburgo, 2018.

WALLACE, Rob. A pandemia e o agronegócio: doenças infecciosas, capitalismo e ciência. São Paulo: Elefante \& Igrá Kniga, 2020.

\section{Sobre as autoras}

RAQUel Raichelis - Assistente social, doutora em Serviço Social e professora do Programa de Estudos Pós-Graduados em Serviço Social.

E-mail: raichelis@uol.com.br

Carola C. Arregui - Assistente social, doutora em Serviço Social e professora do Programa de Estudos Pós-graduados em Serviço Social.

E-mail: carolaarregui@gmail.com 